\title{
BIBLIOTECA: UM CAMINHO PARA A INFORMAÇÃO E O \\ CONHECIMENTO
}

\section{Francinara da Costa Cândido Nivaldo Oliveira}

\section{RESUMO}

Este artigo enfatiza a evolução do uso das bibliotecas em diversas áreas do conhecimento, bem como sua influência na transferência da informação e do conhecimento. Tem como objetivo transformar a biblioteca num centro de convivência para que, os serviços por ela disponibilizados possam ser usufruídos pelos indivíduos que compõem uma sociedade.

\section{PALAVRAS-CHAVE}

Bibliotecas; Informação; Conhecimento

\section{LIBRARY: A WAY FOR THE INFORMATION AND THE KNOWLEDGE}

\begin{abstract}
This article emphasizes the evolution in the use of the libraries in several areas of the knowledge as well as your influence in the transfer of the information and the knowledge. It has as objective to transform the library in a coexistence center so that the severs for it available can be accessed by the individual that compose a society.
\end{abstract}

\section{KEYWORDS}

Libraries; Information; Knowledge 


\section{INTRODUÇÃO}

Durante a Idade Média, a ordem econômica era um dos principais obstáculos para adquirir livros. O pergaminho era obtido por um preço muito alto.

Nos séculos XII e XIII o papel chiffon difundiu-se, respectivamente, na Espanha e França, contribuindo para o declínio do valor do livro. Somente no século XIV e, precisamente no século XV é que o uso do papel pôde ser propagado. Seu custo era de 5 a 13 vezes mais barato que o pergaminho, graças às novas técnicas de papelaria e à multiplicação das oficinas de papel. Porém, o custo das cópias era muito elevado; os bons copistas eram raríssimos naquela época.

Tudo isso favorecia a restrição quanto ao uso das bibliotecas. Os homens de saber e providos de muito dinheiro eram os únicos que possuíam, até o final do século $\mathrm{XV}$, bibliotecas que possuíam importante acervo. Os proprietários as cultivavam com muito esmero. Os livros, conservados dentro de cofres ou armários proclamavam a ciência de seu proprietário.

[...] toda biblioteca de alguma importância possuía um alto valor de mercado. Ela representava uma forma de entesouramento, um capital tanto intelectual quanto financeiro que se pretendia legar aos seus herdeiros, se eles empreendessem seus próprios estudos, fosse num colégio, fosse em alguma igreja. (VERGER, 1999).

Quanto à pequena e média nobreza, mercadores e baixo clero tinham acesso apenas a fragmentos de crônicas, no muito, uma coleção dos estatutos sinodais, o que não podiam ser caracterizados como bibliotecas.

No obscuro norte da Itália, no remoto mosteiro beneditino, como consta no filme O nome da rosa, aos monges era negado e proibido o acesso aos raríssimos e importantes livros que formavam um magnífico acervo. Segundo o padre da ordem, "o ofício do mosteiro era a preservação do conhecimento; preservação, não perscrutação, porque, não existia progresso na história do conhecimento meramente contínua e de sublime recapitulação.”

Esse tipo de preservação era adstringente e punia a quem infringisse a lei, conforme leitura feita pelo estudioso e tradutor grego, intérprete de Venâncio no filme, antes de morrer: "na sabedoria há tristeza; quem amplia seu conhecimento amplia também o seu pesar.” 
Assim morriam os monges do mosteiro: com línguas e dedos manchados de tinta escura e sem obterem conhecimento do magnífico e precioso acervo que adornava a torre do mosteiro. A inquisição sabia como ostentar poder sobre a escrita, informação e a sociedade.

Ao longo dos anos foram surgindo novos paradigmas e, conseqüentemente, mudança de pressupostos básicos no campo do conhecimento. Tendo a sociedade se desprendido do domínio do clero, a sociedade da informação produz o esforço da sociedade na sua construção, através do qual relaciona-se:

Às perspectivas oferecidas pelo novo paradigma de avanços significativos para a vida individual e coletiva, elevando o patamar dos conhecimentos gerados e utilizados na sociedade, oferecendo o estímulo para constante aprendizagem e mudança. (WERTHEIN, 2004).

Hoje, a informação tornou se fundamental para a sociedade e o individuo e não há limites estabelecidos para obtê-la e transformá-la em conhecimento, dependendo, basicamente, da forma como é interpretada e utilizada pelo receptor.

A biblioteca permite ampliar o universo de disseminação das informações, disponibilizando ao público acesso aos materiais que as produzem e profissionais qualificados, como referenciais, no auxílio para obtenção do conhecimento.

\section{A BIBLIOTECA E SUA FUNÇÃO SOCIAL}

O exercício e objetividade nas atividades de uma biblioteca enfatizam a capacidade profissional, intelectual, experimental e estabelece relações com o indivíduo ou grupos de indivíduos que interagem entre si, encontrando respostas e soluções para os mais variados questionamentos.

Adentrar uma biblioteca e nela percorrer caminhos que permitem o acesso as estantes ordenadas sistematicamente e que sustentam informações com fim de produzir conhecimento, propicia aos usuários “o senso da observação e da perspicácia, da ordem e da perfeição [...] e o hábito do julgamento rápido dos problemas.” (FERRAZ, 1949).

O usuário apresenta, gradativamente, novas perspectivas e requer formas inovadoras para obter resposta com maior precisão. Cabe ao profissional bibliotecário ser despojado, autêntico, metódico e disponibilizar seu tempo e conhecimento acrescido às novas 
tecnologias que caracterizam a sociedade atual e fazer da biblioteca um ambiente visível, sociável, interdisciplinar e que não apresente apenas aparência externa mas, sim, uma visualização e contextualização implícita nos diferentes materiais que a compõe, cuja leitura possa ser realizada com o cérebro e com a mente.

Uma biblioteca bem equipada permite não só a obtenção da informação para que se processe em conhecimento, mas, também, para a realização pessoal, a desfragmentação de idéias antônimas, abstratas e utópicas.

Assim sendo, a biblioteca constitui o passaporte para institucionalizar e pluralizar o direito da sociedade à informação, preservar, valorizar e respeitar a cultura de um povo e democratizar a obtenção do conhecimento.

\section{OBJETIVO}

Fazer da biblioteca um centro de convivência, onde a sociedade poderá usufruir a leitura, do lazer, do entretenimento, informação e conhecimento; trabalhar com o intelecto de cada indivíduo com o intuito de desvanecer a concepção de que a biblioteca é um ambiente restrito.

\section{INFORMAÇÃO}

Na década de 40 biólogos efetuavam pesquisas para explicar progressões contidas nos cromossomos humanos. Em decorrência disso, a palavra informação passou a ser utilizada e disseminada, junto às organizações, quando o Matemático Americano Claude Elwood Shannon desenvolveu a Teoria da Matemática da Comunicação ${ }^{1}$.

O acúmulo de informações hoje produzidas, devido ao grande avanço tecnológico, transformações sociais, econômicas, culturais e a expansão política, tem gerado um certo desconforto por parte de quem recebe. Isto porque, para retê-la e absorvê-la torna mais difícil quando não se sabe qual método utilizar para efetivá-la. A biblioteca, juntamente com seus profissionais são os grandes responsáveis para adequarem o método à prática.

\footnotetext{
${ }^{1}$ Esta teoria apresenta a circulação da informação entre indivíduos e que os elementos: emissor, receptor, fonte, mensagem e meio.
} 
[...] a informação não é algo que chega até nós e nos deixa ilesos. Ao contrário, chega e quase que automaticamente é processada e provoca alguma transformação ainda que mínima ou sem maiores consequiências (CARVALHO; TAVARES, 2001).

Através da linguagem a informação é transmitida de indivíduo para indivíduo, de indivíduo para grupos ou vice-versa. Nos gestos e manifestações como sentar, sorrir, chorar, andar, falar, declamar, conversar, dentre outros, encontramos informação ou informações a serem propagadas e/ou processadas. Veículos como rádio, tv, Internet, etc..., apresentam características para redimensionarem e redistribuírem essa(s) informação(ões). E, por que não a biblioteca?

Sabemos que sua existência se dá para o construto recreativo, intelectual, moral e cognitivo de um indivíduo, pois, a informação é disseminada desde a entrada, indicando nome, horário de funcionamento, histórico, pessoas que contribuíram para sua formação até o espaço abrigado pela última estante que sustêm um número indescritível de palavras, expressões, frases e textos.

Enfatizando essa analogia, numa entrevista a VEJA (1999), o ensaísta canadense Alberto Manguel diz que "o processo de pesquisa em bibliotecas leva rapidamente ao tipo de informação que se busca”.

\section{CONHECIMENTO}

A sistematização do conhecimento dentro e fora das cidades européias compreendia o processo de compilar, checar, editar, traduzir, comentar, criticar e sintetizar. O mesmo era considerado o produto da transformação das novas informações adquiridas pelos letrados da época.

A informação chegava até eles constituída de conceitos ou categorias que eram assimilados ou adaptados às categorias da cultura européia. As cidades eram então denominadas de centros de cálculo². Um exemplo é o da antiga Alexandria que, com sua famosa biblioteca, estudiosos como o geógrafo Eratóstenes transformavam o conhecimento

\footnotetext{
${ }^{2}$ Lugares em que a informação local de diferentes regiões e relativa a diferentes tópicos era transformada em conhecimento geral na forma de mapas, estatísticas, etc...
} 
local em conhecimento geral. Em Florença, Roma e Paris, graças a existência de bibliotecas e professores, cidades universitárias puderam desempenhar um papel incalculável na elaboração do conhecimento - Pádua e Montpellier (séc. XVI): contribuíram para o conhecimento médico, Leiden (séc. XVII): para a botânica e estudos arábicos, Gottingen (séc. XVIII): para a história e estudos russos, etc... .

Morin (2002, p. 35), diz que:

O conhecimento do mundo como mundo é necessidade, ao mesmo tempo, intelectual e vital. É o problema universal de todo cidadão do novo milênio: como ter acesso às informações sobre o mundo e como ter a possibilidade de articulá-las e organizá-las? Como perceber e conceber o Contexto, o Global (a realidade todo/partes), o Multidimensional, o Complexo? Para articular e organizar os conhecimentos e assim reconhecer e conhecer os problemas do mundo, é necessária a reforma do pensamento. Entretanto, esta reforma é paradigmática e, não, programática: é a questão fundamental da educação, já que se refere à nossa aptidão para organizar o conhecimento.

Em virtude disso, para tornar o conhecimento pertinente ao receptor, a biblioteca exerce um papel indispensável e de grande influência sobre os membros que constituem uma sociedade: disponibilizar pessoal qualificado e materiais necessários, disseminar leitura, executar serviços de documentação, projetar informações e dados em seus contextos para que adquiram sentidos.

A evolução cognitiva não caminha para o estabelecimento de conhecimentos cada vez mais abstratos, mas, ao contrário, para sua contextualização. “[...] a contextualização é condição essencial da eficácia (do conhecimento cognitivo).” (MORIN, 2002).

Conhecer sem contextualizar não edifica o homem, sendo assim, a biblioteca, junto aos profissionais e serviços, atua como intermediária entre o usuário, a informação e o processo de aquisição do conhecimento, afim de que este tenha livre arbítrio para questionar, sugerir e demonstrar as dificuldades advindas dos meios externos à biblioteca.

Conhecer requer algo mais, que é reunir as informações acessadas considerando-se um objetivo ou realidade, e, a partir destes, organizá-las de um modo lógico, que permita a produção de um novo entendimento sobre o assunto que gerou o estudo. Em suma, conhecer exige a capacidade interpretativa do homem. (CARVALHO;TAVARES, 2001).

Capacidade esta que é deliberada a cada nova informação que é disponibilizada, interpretada e organizada de forma lógica. Essa é a sociedade do conhecimento onde o diferencial está na capacidade da interpretação humana. 


\section{EXPANSÃO QUANTO AO USO DE BIBLIOTECAS}

Nos últimos anos a biblioteca bem como seu arranjo interno, tem sido muito enfatizada em diversos meios de comunicação, abordando diferentes áreas e diferentes estilos: músicas, filmes, novelas, teatros, empresas, instituições, etc..., traduzem essa afirmativa, contribuindo para minimizar o número de pessoas que ainda sentem inseguros ou ignoram o papel da biblioteca na sociedade.

Atualmente existem projetos de instituições publicas e privadas que implantaram bibliotecas em suas dependências com o objetivo de transformá-las em centros de vivencias e proporcionar a seus funcionários um ambiente de cultura, laser e estudos.

Abaixo fazemos alguns relatos:

- MABEL

Segunda maior produtora de biscoitos da América Latina, a Mabel criou o centro de convivência, referência de cidadania e dignidade. Através deste centro, oferece a todos os funcionários benefícios como programas de saúde, refeitório com alimentação balanceada e orientada, salão de jogos, cinema e uma biblioteca, que teve início através de doações feitas pelos membros da sociedade, de livros e periódicos, com intuito de proporcionar aos funcionários, os quais terminam a jornada de trabalho e se deslocam diretamente para escolas e universidades, local apropriado para realizarem seus estudos. Hoje, há um alto índice de freqüência na Biblioteca por parte dos funcionários que realizam pesquisas, estudos, leitura para lazer e entretenimento.

- INEP - Instituto Nacional de Estudos e Pesquisas Educacionais Anísio Teixeira

Criado, por lei, em 1937, recebeu inicialmente o chamado de Instituto Nacional. Em 1985 o Inep passou por um novo desenho institucional. Foi estabelecido um processo de reestruturação e redefinição de sua missão centrada na reorientação das políticas de apóio a pesquisas educacionais e no reforço do processo de disseminação de informações educacionais, incorporando novas modalidades de produção e difusão de conhecimento e informação. Ligado à Diretoria de Tratamento e Disseminação de Informações educacionais do Inep, o Cibec - Centro de Informação e Biblioteca em Educação, é responsável pela disseminação de informações educacionais, que podem ser primárias (produzidas pelo próprio 
Inep), secundárias (fornecidas por instituições educacionais públicas e privadas) e terciárias (informações primárias e secundárias que receberam tratamento ou agregação de valor). O Cibec é um centro dinâmico que procura acompanhar a evolução tecnológica, de maneira a produzir constantemente, novos produtos e serviços com vistas a responder aos imperativos da diversidade dos perfis de seus usuários e dos veículos de disseminação.

- IRB - Instituto de Resseguros do Brasil

O IRB surgiu em 1939, graças ao Presidente Getúlio Vargas. Naquela época, a atividade de resseguro era feita quase que total no exterior, de forma direta ou por intermédio de companhias estrangeiras que operavam no Brasil. A necessidade de favorecer o aumento da capacidade seguradora das sociedades nacionais, para a retenção de maior volume de negócios em nossa economia tornava urgente a organização de uma entidade nacional de resseguro. O chefe de Inspetoria de Seguros, Sr. Antônio Félix de Faria Albernaz, , era dono de um acervo que continha uma preciosa coleção de obras técnicas. Assim, a Biblioteca Albernaz, começou seu próprio acervo, inaugurada em 1940. Reconhecendo o setor como importante elemento de apóio, o presidente José Lopes de Oliveira, ampliou e modernizou a biblioteca em 1974. Em 1990 ocorreu uma reestruturação organizacional na empresa e a biblioteca foi incorporada à estrutura da Secretaria Geral da Presidência (SGP). Hoje, denominada de Biblioteca de Seguros Rodrigo Médicis, em homenagem ao Dr. Rodrigo de Andrade Médicis, é considerada a maior biblioteca de seguros e resseguros da América Latina, por seu acervo valioso e atendimento a todo mercado segurador brasileiro e de outros países. Seu acervo é formado em média de 12 mil livros e 686 periódicos.

\section{CONCLUSÃO}

A história da sociedade humana é marcada de várias experiências, manifestações e imposições. Mesmo sendo privado do acesso a informação, o homem, não perdeu seu espírito critico e cognitivo como integrante da sociedade. Sociedade esta constituída cada vez mais de informações, transformações e novos conhecimentos.

A biblioteca é uma organização formalmente estruturada para fornecer bens necessários para homens e sua sobrevivência: a leitura, a informação, o conhecimento acumulado nos registros bibliográficos, multimeios e redes de computadores como meio de ligação (Internet/Intranet) dando suporte no contexto da sociedade da informação, pois, 
conforme a análise do historiador Roger Chartier, ela é "símbolo da cumulação do saber", onde existe a "percepção de obra como obra em sua existência, coerência e identidade”, assumindo assim item de grande importante em empresas.

A razão para este fato, tem relação direta com os desafios da evolução da sociedade contemporânea, caracterizada essencialmente, pela reconhecida e certificada importância que a informação e o conhecimento assume perante a realidade atual, refletindo em iniciativas para criação de bibliotecas voltadas para funcionários de empresas publicas e privadas.

\section{REFERÊNCIAS}

BARKER, J. A. Mudanças de paradigmas. In: __. Contabilidade de ganhos: a nova contabilidade gerencial de acordo com a teoria das restrições. São Paulo: Nobel, 1997.

BURKE, P. Uma história social do conhecimento: de Gutemberg a Diderot. Rio de Janeiro: Jorge Zahar, 2003.

CARVALHO, G. M. R.; TAVARES, M. S. Informação \& Conhecimento: uma abordagem organizacional. Riod de Janeiro: Qualitymark, 2001.

CARVAlHO, S. O facilitador da informação, O Tempo, Belo Horizonte, 2 nov, 2003. Caderno Emprego.

FERRAZ, W. A biblioteca. 3. ed. São Paulo: Saraiva, 1949.

FERREIRA, Aurélio Buarque de Holanda. Novo dicionário da língua portuguesa. 2. ed. Rio de Janeiro: Nova Fronteira, 1986.

FONSECA, E. N. A biblioteconomia brasileira no contexto mundial. Rio de Janeiro: Tempo Brasileiro, 1979.

INSTITUTO NACIONAL DE ESTUDOS E PESQUISAS EDUCACIONAIS ANÍSIO TEIXEIRA. Disponível em : <http://www.inep.gov.br/institucional/historia.htm>. Acesso: 14 dez. 2004.

INSTITUTO DE RESSEGUROS DO BRASIL. Disponível em: http://www.irb.com.br. Acesso em: 15 dez. 2004.

LARA, M. L. G.; CONTI, V. L. Disseminação da informação e usuários. São Paulo em Perspectiva. São Paulo, v. 17, n. 3-4, p. 26-34 2003.

LER é poder. Veja, São Paulo, v. 32, n. 27, p. 11-15, 1999. 
LIVELY, L. Como gerenciar informações. Rio de Janeiro: Campus, 2002.

MABEL: melhor impossível. Disponível em: <http://www.mabel.com.br/novo/empresa estrutura.htm>. Acesso em: 14 dez. 2004.

MCGARRY, K. O contexto dinâmico da informação: uma análise introdutória. Brasília: Briquet de Lemos, 1999.

MORIN, E. Os setes saberes necessários à educação do futuro. 5. ed. São Paulo: Cortez, 2002.

NOVAES, W. A quem pertence à informação?. 2. ed. Petrópolis: Vozes, 1996.

O NOME da rosa. [São Paulo]: Videolar Multimídia, 1986. 1 videocassete (130 min.): NTSC/ VHS: son., color.

RIBONI, E. A nojenta história do cristianismo : a página negra do cristianismo: 2000 anos de crimes, terror e repressão. SEITA Hell. Disponível em: <http://www.seitahell.hpg.ig.com.br/ cristianismo.html>. Acesso: 15 out. 2004.

VERGER, J. Os livros na idade média. In: . Homens e saber na idade média. Bauru/sp: Edusc, 1999.

WERTHEIN, J. A sociedade da informação e seus desafios. Ciência da Informação. Brasília, v. 29, n. 2, maio./ago. 2000.

FRANCINARA DA COSTA CÂNDIDO

Especialista em gestão do conhecimento - UNIFOR/MG,

Bacharel em Biblioteconomia - ESBI/MG,

PUC Minas Arcos.

Av. JK, 474F-Bairro Brasília/Arcos-MG - 35588-000

E-mail:francosta@pucminas.br; Nara.costa123@bol.com.br

NIVALDO OLIVEIRA

Bibliotecário do Sistema de Bibliotecas da

Pontifícia Universidade Católica de Minas Gerais, Graduado e

Especializando em Gestão do conhecimento e

Tecnologia da Informação pelo UNIFOR/MG.

Av. Carmelita de Castro, 420 - Birro José Honorato de Castro, Formiga/MG -

35570-000

E-mail: nivaldobk@pucminas.br

Recebido em: 26/06/2005

Aceito em: 12/12/2005 